\title{
Infectious background of febrile advanced lung cancer patients who received chemotherapy
}

\author{
KATSUHIRO MASAGO $^{1}$, AKIKO FUKUHARA ${ }^{1}$, YUTAKA ITO ${ }^{1}$, YUKIMASA HATACHI ${ }^{1}$, \\ KAORU IRISA ${ }^{1}$, YUICHI SAKAMORI ${ }^{1}$, YOSUKE TOGASHI ${ }^{1}$, SHIRO FUJITA ${ }^{2}$, \\ YOUNG HAK KIM ${ }^{1}$, TADASHI MIO ${ }^{1}$ and MICHIAKI MISHIMA ${ }^{1}$ \\ ${ }^{1}$ Department of Respiratory Medicine, Graduate School of Medicine, Kyoto University, Kyoto; \\ ${ }^{2}$ Division of Integrated Oncology, Institute of Biomedical Research and Innovation, Kobe, Japan
}

Received April 15, 2010; Accepted June 17, 2010

DOI: 10.3892/ol_00000150

\begin{abstract}
The study aimed to determine the diagnostic utility of procalcitonin (PCT) in order to discriminate between infective fever and fever due to inflammation in febrile advanced lung cancer patients treated with cytotoxic chemotherapy. A total of 121 patients with advanced lung cancer, treated with a cytotoxic chemotherapy regimen between September 2007 and September 2008 at Kyoto University Hospital, were recruited. Blood samples were obtained on the first day of the fever. Serum c-reactive protein (CRP) and PCT levels were measured. At least two blood cultures were performed, and sputum was taken for Gram staining and culture. There were 71 episodes in 61 patients in the 12 months of the study, representing $50.4 \%$ of our study population. A total of 41 patients $(57.7 \%)$ were diagnosed with pneumonia using imaging modalities, $6(8.5 \%)$ with bacteremia using blood culture and 4 (5.6\%) with urinary tract infections using urine culture. Among the 41 pneumonia cases, culture from sputum revealed pathologic bacteria in 21 (51.2\%) and fungal disease in 14 (34.1\%) cases. Among the 71 febrile episodes, serum procalcitonin and CRP were measured in 50 episodes. Serum procalcitonin-positive patients showed poor outcomes on antibiotics therapy (Fisher's exact test, $\mathrm{p}=0.042$ ). Furthermore, serum procalcitonin positivity was able to discriminate infective fever from fever due to inflammation (Chi-square test, $\mathrm{p}=0.001$ ). We showed the causative organisms of febrile advanced lung cancer patients who received cytotoxic chemotherapy, as well as the possibility of PCT to discriminate infective fever from fever due to inflammation.
\end{abstract}

\section{Introduction}

Treatment of infection using antimicrobial drugs is based on data generated with prophlogistic bacteria. Currently, medical

Correspondence to: Dr Katsuhiro Masago, 54 Syogoin-Kawaracho, Sakyo-ku, Kyoto 606-8507, Japan

E-mail: masago@kuhp.kyoto-u.ac.jp

Key words: pneumonia, advanced lung cancer, procalcitonin, immunocompromised host, c-reactive protein, prognosis treatment strategy is determined according to the guidelines for management (1). A treatment guideline for nosocomial pneumonia and febrile neutropenia (1) exists, but the data implicating a causative agent at the time of pyrexia in a tumorbearing stage are not available. Therefore, a recommended treatment guideline is absent in such conditions.

Lung cancer is a leading cause of cancer-related mortality worldwide and is expected to remain a major health concern for the foreseeable future. The majority of patients with nonsmall cell lung cancer (NSCLC) are in advanced stages at diagnosis and most are treated with cytotoxic agents such as those used in patients with small cell lung cancer (SCLC) (2). The majority of cytotoxic agents for anticancer therapy also adversely affect normal cells. It is assumed that these unfavorable effects primarily impact rapidly proliferating cells, such as bone marrow cells.

Increased susceptibility to infection and difficulty in treatment due to neutropenia after cytotoxic anticancer drug administration is a serious concern in terms of chemotherapeutic continuation. Fever in neutropenic patients is a frequent complication of chemotherapy. It occurs in $10-50 \%$ of patients with solid tumors and in $80 \%$ of those with blood malignancies. It usually requires treatment for 7-12 days, at an approximate daily cost of more than US $\$ 1,500$ and is associated with a mortality rate of almost $10 \%$. Thus, febrile neutropenia affects an increasing number of individuals worldwide and poses a significant burden on health care and its economy (3). Even without neutropenia, respiratory tract infection can be precipitated by lung cancer, thereby disordering pulmonary local blood and air flow. In addition, it appears that degradation of the immunologic status occurs from aggravation of the host nutritional status. When general steroids are used for the therapeutic purpose of edematous reduction of metastases to the brain, nausea and vomiting can also cause a degradation of the immunologic state.

Cytotoxic anticancer drugs are usually administered to advanced lung cancer patients, and fever increases the difficulty in treatment continuation. The frequency of infectious diseases in advanced lung cancer patients, regardless of the administration of anticancer drugs, appears to be higher than in healthy individuals. However, it is difficult to diagnose an infectious disease in advanced lung cancer patients during 
Table I. Characteristics of the febrile patients $(n=61)$.

\begin{tabular}{ll}
\hline Patient characteristics & No. of cases $(\%)$ \\
\hline Age (years) & $35-82$ \\
Median & 69 \\
Gender & \\
Female & $11(18.0)$ \\
Male & $50(82.0)$ \\
Smoking status & \\
Non-smoker & $8(13.1)$ \\
Smoker & $53(86.9)$ \\
Former & $19(28.4)$ \\
Current & $34(58.5)$ \\
Tumor histology & \\
Adenocarcinoma & $24(39.3)$ \\
Squamous cell carcinoma & $10(16.4)$ \\
NSCLC & $4(6.6)$ \\
Small cell carcinoma & $23(37.7)$ \\
Pathologic stage & \\
IIIA & $11(18.0)$ \\
IIIB & $18(29.5)$ \\
IV & $32(52.5)$ \\
\hline
\end{tabular}

NSCLC, non-small cell lung cancer.

chemotherapy as no epidemiological investigative studies regarding infection in lung cancer patients currently exist. Therefore, it is difficult to determine whether pyrexia or the tumor itself is the cause of infection.

Procalcitonin (PCT), a glycoprotein, is the propeptide of calcitonin. It is devoid of hormonal activity. It consists of 116 amino acids, has a molecular weight of $13 \mathrm{kDa}$ (4) and, under normal circumstances, is produced in the $\mathrm{C}$ cells of the thyroid gland. PCT is then cleaved via a specific protease to calcitonin, katacalcin and an N-terminal residue (5). In contrast to the short half-life of calcitonin (10 min), PCT has a long half-life of 25-30 h in serum (6). In healthy humans, PCT levels are undetectable $(<0.1 \mathrm{ng} / \mathrm{ml})$. Severe generalized bacterial, parasitic or fungal infections with systemic manifestation are associated with increased PCT serum levels. Karzai et al reported that PCT may be a superior marker in infections with systemic manifestation (6).

Therefore, this study investigated the infectious background of the febrile advanced lung cancer patients who received chemotherapy. The value of PCT and c-reactive protein (CRP) in the differential diagnosis of febrile conditions in patients with advanced lung cancer was also evaluated.

\section{Materials and methods}

Study population. A total of 121 patients with advanced lung cancer who were treated with a cytotoxic chemotherapy regimen between September 2007 and September 2008 at Kyoto University Hospital were recruited. Written informed
Table II. Results of identified causes of 71 episodes in 61 cases.

\begin{tabular}{lr}
\hline Causes & No. of e \\
\hline Pneumonia & 6 \\
Streptococcus pneumoniae & 4 \\
Clamidya pneumoniae & 3 \\
MRSA & 2 \\
Moraxella catarrhalis & 2 \\
Klebsiella pneumoniae & 1 \\
Staphylococcus aureus & 1 \\
Pseudomonas aeruginosa & 1 \\
Streptococcus G & 1 \\
Pseudomonas fluorescens &
\end{tabular}

Fungal diseases

Aspergillosis

Pneumocystis jiroveci

Candidiasis

Causative fungus unknown

Cytomegalo virus

Cause unknown

4

3

2

2

1

1

1

1

Bacteremia

E. coli

4

4

1

5

1

5

Streptococcus pyrogen $\quad 1$

Streptococcus epidermis $\quad 1$

Streptococcus $G \quad 1$

Staphylococcus aureus $\quad 1$

Urinary tract infection

Staphylococcus agalactiae $\quad 1$

Enterococcus faecalis $\quad 1$

Coaglase-negative streptococcus 1

E. coli 1

Cause unknown $\quad 20$

Total $\quad 71$

MRSA, methicillin-resistant Staphylococcus aureus.

consent pertaining to the utilization of clinical materials was obtained from all patients. The study was approved by the Ethics Committee of the Kyoto University Graduate School and Faculty of Medicine. The inclusion criteria involved an advanced lung cancer patient undergoing cytotoxic chemotherapy with systemic infection based on any of the following characteristics: fever $\left(>38^{\circ} \mathrm{C}\right)$ with cough, rapid breathing, difficulty in breathing or convulsions and with a clinical diagnosis of pneumonia or sepsis. Laboratory evaluation for blood, sputum and urine culture were collected from the patients as part of the usual routine investigations conducted. The patients were in the nosocomial setting. Nosocomial pneumonia is defined as pneumonia occurring $\geq 48 \mathrm{~h}$ after admission (7).

Laboratory methods. Blood samples obtained on the first day of fever were stored at $-80^{\circ} \mathrm{C}$ until the serum PCT and CRP levels were measured. The serum CRP level was determined using the 


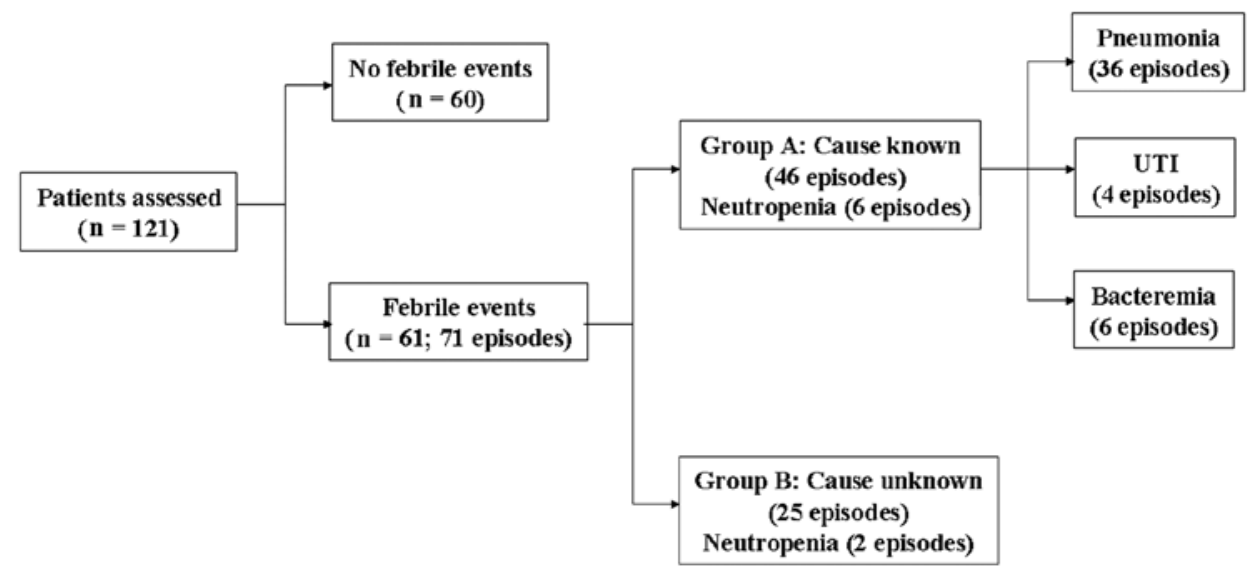

Figure 1. Precise data of the febrile episodes. UTI, urinary tract infection.

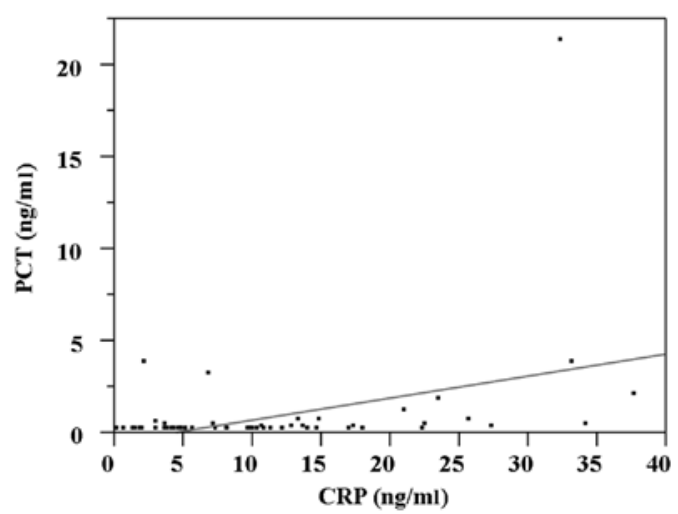

Figure 2. Association between serum CRP and pro-carcitonin; $r=0.38$, $\mathrm{p}=0.0045$.

nephelometric method and the serum PCT level was measured by the Lumi test-PCT (ILMA Kits BRAHMS Diagnostica $\mathrm{GmbH}$, Berlin, Germany). The analytical assay sensitivity was $\sim 0.1 \mathrm{ng} / \mathrm{ml}$. At least two blood cultures were performed. Sputum was obtained for Gram staining and culture and subsequently analysed by Taq Man real-time PCR for Mycoplasma pneumoniae, Legionella pneumophila and Chlamydophyla psittaci (8). Urine was sampled for antigen testing on Streptococcus pneumoniae and Legionella pneumophila (Binax NOW; Binax, Scarborough, ME, USA) $(9,10)$.

\section{Results}

Patient characteristics. Table I shows the characteristics of the 61 advanced lung cancer patients who were admitted to our institution between June 2007 and June 2008. The patients were Japanese, and included $50(83.3 \%)$ males and $10(16.7 \%)$ females, with a median age of 69 years (range 35-80). Of the 61 patients, $8(11.5 \%)$ were non-smokers and $53(88.3 \%)$ were former or current smokers. The patients were treated with cytotoxic agents in the febrile stage. The pathologic diagnoses and disease stage are listed in Table I. There were 71 episodes in 61 patients during the 12 months of the study, i.e., $50.4 \%$ of our study population. Of the 71 episodes, causative agents were found in 46 episodes, including 6 neutropenia cases (Fig. 1,

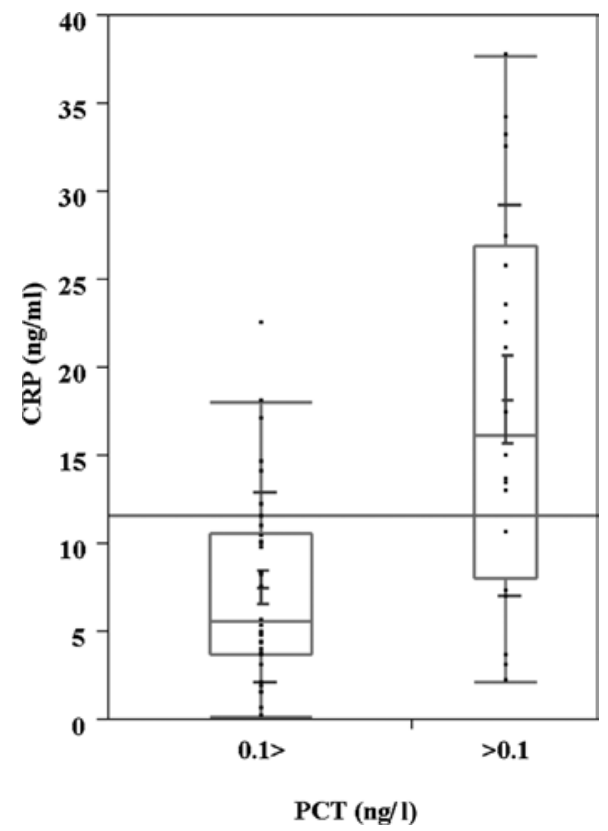

Figure 3. Serum CRP according to the serum pro-carcitonin level.

Group A). No causative agents were found in 25 episodes, including 2 neutropenia cases (Fig. 1, Group B). Table II shows the organisms isolated in sputum, blood and urine. A total of 41 patients $(57.7 \%)$ were diagnosed with pneumonia using imaging modalities, $6(8.5 \%)$ with bacteremia using blood culture and 4 patients $(5.6 \%)$ with urinary tract infection using urine culture. Among the 41 pneumonia cases, culture from sputum revealed pathologic bacteria in $21(51.2 \%)$ cases, fungal disease in $14(34.1 \%)$ and cytomegalovirus in $1(2.5 \%)$ case. Antibiotic treatment was prescribed for all 41 cases.

Serum inflammation markers. Among the 71 febrile episodes, serum PCT and CRP were measured in 50 cases. Serum CRP was elevated beyond the cut-off level of our institute $(0.2 \mathrm{mg} /$ dl) in $69(97.2 \%)$ cases. Serum CRP correlates with serum PCT (Fig. 2; r=0.38, p=0.0045). According to the cut-off level of serum PCT $(0.1 \mathrm{ng} / \mathrm{ml})$, serum CRP was higher in the PCT-positive patients (Fig. 3). Serum PCT was also higher 
A

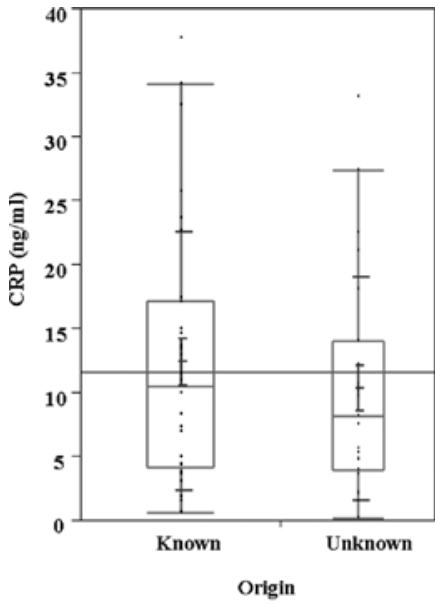

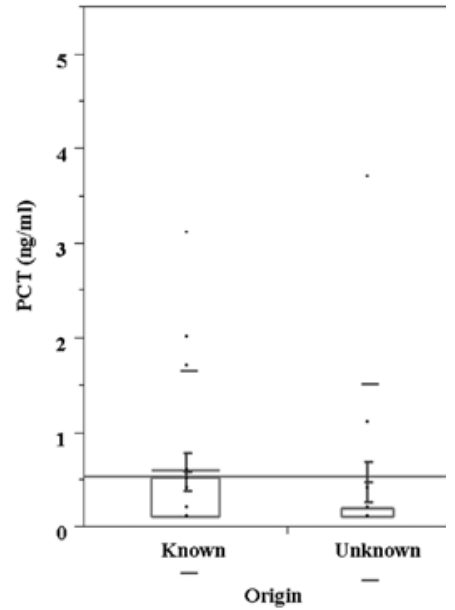

Figure 4. (A) Serum CRP and (B) PCT according to causative organisms.

Table III. Treatment outcomes of 25 cases with known cause according to pro-carcitonin.

$\begin{array}{cc}\begin{array}{c}\text { No. of } \\ \text { episodes }\end{array} & \begin{array}{c}\text { Treatment response } \\ \text { of antibiotics }\end{array}\end{array}$

Improved Deceased

\begin{tabular}{lccc}
\hline Negative $<0.1 \mathrm{ng} / \mathrm{ml}$ & 14 & 13 & 1 \\
Positive $>0.1 \mathrm{ng} / \mathrm{ml}$ & 11 & 8 & 3 \\
Total & 25 & 21 & 4 \\
\hline
\end{tabular}

Fisher's exact test; $\mathrm{p}=0.287$.

Table IV. Treatment outcomes of 50 episodes according to pro-carcitonin.

$\begin{array}{cc}\begin{array}{c}\text { No. of } \\ \text { cases }\end{array} & \begin{array}{c}\text { Treatment response } \\ \text { of antibiotics }\end{array}\end{array}$

Improved Deceased

\begin{tabular}{llll}
\hline Negative $<0.1 \mathrm{ng} / \mathrm{ml}$ & 32 & 30 & 2 \\
Positive $>0.1 \mathrm{ng} / \mathrm{ml}$ & 18 & 12 & 6 \\
Total & 50 & 42 & 8 \\
\hline
\end{tabular}

Fisher's exact test; $\mathrm{p}=0.039$.

than serum CRP in the population whose cause of infection was known (Fig. 4). Although serum PCT did not correlate with treatment outcome among the 25 cases with known causes (Table III), serum PCT-positive patients showed a poor outcome with antibiotics therapy in Table IV (Fisher's exact test, $\mathrm{p}=0.039$ ). Furthermore, serum PCT positivity was likely to discriminate between infective fever and fever due to inflammation (Table V) (Chi-squared test, $\mathrm{p}=0.018)$. According to the cut-off level of serum PCT, the duration of the febrile state did not correlate with the serum PCT level (data not shown).
Table V. Infectious origins of 50 episodes according to procarcitonin.

\begin{tabular}{lccc}
\hline & No. of cases & \multicolumn{2}{c}{ Infectious origin } \\
\cline { 3 - 4 } & & Known & Unknown \\
\hline Negative $<0.1 \mathrm{ng} / \mathrm{ml}$ & 32 & 13 & 19 \\
Positive $>0.1 \mathrm{ng} / \mathrm{ml}$ & 18 & 14 & 4 \\
Total & 50 & 27 & 23 \\
\hline
\end{tabular}

Chi-square test; $\mathrm{p}=0.018$

\section{Discussion}

This study examined the infectious background of patients with advanced lung cancer who received cytotoxic chemotherapy. Among the serum PCT-positive population, causative agents are more readily identified. Serum PCT levels correlate with serum CRP levels. In our study population, the positive serum PCT resulted in poor clinical outcome.

To the best of our knowledge, this is the first study analyzing PCT plasma levels and infectious background in advanced lung cancer patients receiving chemotherapy. Cultures from sputum yielded pathogenic bacteria in 21 episodes $(29.6 \%)$. Gram-negative bacteria accounted for $66.7 \%$ and gram-positive organisms for $33.3 \%$ of all microorganisms recovered.

Nosocomial pneumonia occurs following admission to the hospital. This type of pneumonia was neither present nor in a period of incubation at the time the patient was admitted (11). Nosocomial pneumonia is the leading cause of death from hospital-acquired infections and thus a major public health concern. The estimated prevalence of nosocomial pneumonia within the Intensive Care Unit ranges from 10 to $65 \%$, with case fatality rates ranging from $20-55 \%$ in the majority of reported findings $(1,12,13)$. When pneumonia arises in the hospitalized patient, aerobic gram-negative bacilli, particularly Pseudomonas aeruginosa, Enterobacter sp. and Staphylococcus aureus are the major causative organisms (14). Other common causes of nosocomial pneumonia include 
Hemophils influenzae, Streptococcus pneumoniae, aspiration with anaerobes, Legionella sp. and viruses. Respiratory syncytial virus, influenza $\mathrm{A}$ and $\mathrm{B}$, and parainfluenza are responsible for more than $70 \%$ of nosocomial viral disease (14). Although there appears to be little difference between the bacterial background in nosocomial pneumonia with normal hosts and our study population (Table II), the frequency of fungal disease or the rate of detection of pneumococcal pneumonia in our study was relatively high. Consequently, a larger sample may result in more accurate information concerning the causes of microbacterium in our study population, thereby aiding in the treatment modality to be used.

PCT was previously proposed as a new marker of severe bacterial infection $(6,15,16)$ that may be particularly useful in the discrimination between septic complication and non-infectious fever in transplant patients (17). Although PCT appears to be ubiquitously produced by the body, initial concerns were that, as in the case of traditional cytokines, PCT is produced mainly by white blood cells. PCT concentrations rise in neutropenia to similar concentrations to those observed in immunocompetent patients $(18,19)$. However, the usefulness of PCT in the detection of infection in such patients remains to be elucidated. Higher concentrations, such as $2.5 \mathrm{mg} / 1$ (20) or $5.0 \mathrm{mg} / 1$ (18), are suggestive of severe sepsis over bacteremia and localized infection but low concentrations do not necessarily exclude infection. This phenomenon depends on the causative organism with PCT responses noted in cases of gram-positive cocci and gram-negative bacteremia, but not coagulase-negative staphylococcus (18). It is likely that the value of PCT in febrile neutropenics is in monitoring the response to therapy rather than diagnosis. However, this finding is not universal, since it has been noted that PCT may remain low despite evidence of significant infection (19,21). Furthermore, PCT does not discriminate between causes of fever early in the illness (22) and is unable to distinguish between fungal and bacterial infection (19). However, in our study, serum PCT positivity was able to discriminate between infective fever and fever due to inflammation since the serum PCT was higher than that of CRP in the population whose cause of infection was known.

The limitations of our study, however, include small sample size, heterogeneity of treatment regimens and its retrospective nature. Alternative methods, such as TRACE, appear to be more sensitive than the lumi test (23). However, we showed the causative organisms of febrile advanced lung cancer patients who received cytotoxic chemotherapy. The ability of PCT to discriminate between infective fever and fever due to inflammation was also demonstrated. It can therefore be concluded that a prospective clinical trial is required in order to evaluate whether antibiotics should be employed on febrile advanced lung cancer patients during cytotoxic chemotherapy treatment according to their serum PCT levels.

\section{References}

1. Guidelines for the management of adults with hospital-acquired, ventilator-associated, and healthcare-associated pneumonia. American Thoracic Society. Am J Respir Crit Care Med 171: 388-416, 2005

2. Pfister DG, Johnson DH, Azzoli CG, et al: American society of clinical oncology treatment of unresectable non-small-cell lung cancer guideline: update 2003. J Clin Oncol 22: 330-353, 2004.
3. Klastersky J: Management of fever in neutropenic patients with different risks of complications. Clin Infect Dis 39 (Suppl 1): S32-S37, 2004

4. Jacobs JW, Lund PK, Potts JT Jr, Bell NH and Habener JF: Procalcitonin is a glycoprotein. J Biol Chem 256: 2803-2807, 1981.

5. Le Moullec JM, Jullienne A, Chenais J, et al: The complete sequence of human preprocalcitonin. FEBS Lett 167: 93-97, 1984.

6. Karzai W, Oberhoffer M, Meier-Hellmann A and Reinhart K: Procalcitonin - a new indicator of the systemic response to severe infections. Infection 25: 329-334, 1997.

7. Hospital-acquired pneumonia in adults: diagnosis, assessment of severity, initial antimicrobial therapy, and preventive strategies. A consensus statement, American Thoracic Society, November 1995. Am J Respir Crit Care Med 153: 1711-1725, 1996.

8. Herpers BL, De Jongh BM, van der Zwaluw $\mathrm{K}$ and van Hannen EJ: Real-time PCR assay targets the 23s-5s spacer for direct detection and differentiation of legionella spp. and legionella pneumophila. J Clin Microbiol 41: 4815-4816, 2003.

9. Helbig JH, Uldum SA, Bernander S, et al: Clinical utility of urinary antigen detection for diagnosis of community-acquired, travel-associated, and nosocomial legionnaires' disease. J Clin Microbiol 41: 838-840, 2003.

10. Smith MD, Derrington P, Evans R, et al: Rapid diagnosis of bacteremic pneumococcal infections in adults by using the binax now streptococcus pneumoniae urinary antigen test: a prospective, controlled clinical evaluation. J Clin Microbiol 41: 2810-2813, 2003

11. Finch RG and Woodhead MA: Practical considerations and guidelines for the management of community-acquired pneumonia. Drugs 55: 31-45, 1998.

12. Ibrahim EH, Ward S, Sherman G and Kollef MH: A comparative analysis of patients with early-onset vs. late-onset nosocomial pneumonia in the ICU setting. Chest 117: 1434-1442, 2000.

13. Kollef MH: The prevention of ventilator-associated pneumonia. N Engl J Med 340: 627-634, 1999.

14. Taylor GD, Buchanan-Chell M, Kirkland T, McKenzie M and Wiens R: Bacteremic nosocomial pneumonia. A 7-year experience in one institution. Chest 108: 786-788, 1995.

15. Assicot M, Gendrel D, Carsin H, Raymond J, Guilbaud J and Bohuon C: High serum procalcitonin concentrations in patients with sepsis and infection. Lancet 341: 515-518, 1993.

16. Gendrel D, Raymond J, Coste J, et al: Comparison of procalcitonin with c-reactive protein, interleukin 6 and interferon-alpha for differentiation of bacterial vs. viral infections. Pediatr Infect Dis J 18: 875-881, 1999.

17. Kuse ER, Langefeld I, Jaeger K and Kulpmann WR: Procalcitonin in fever of unknown origin after liver transplantation: a variable to differentiate acute rejection from infection. Crit Care Med 28: $555-559,2000$

18. Giamarellou H, Giamarellos-Bourboulis EJ, Repoussis P, et al: Potential use of procalcitonin as a diagnostic criterion in febrile neutropenia: experience from a multicentre study. Clin Microbiol Infect 10: 628-633, 2004.

19. Hambach L, Eder M, Dammann E, et al: Diagnostic value of procalcitonin serum levels in comparison with c-reactive protein in allogeneic stem cell transplantation. Haematologica 87: 643-651, 2002.

20. Giamarellos-Bourboulis EJ, Grecka P, Poulakou G, Anargyrou K, Katsilambros $\mathrm{N}$ and Giamarellou $\mathrm{H}$ : Assessment of procalcitonin as a diagnostic marker of underlying infection in patients with febrile neutropenia. Clin Infect Dis 32: 1718-1725, 2001.

21. Blijlevens NM, Donnelly JP, Meis JF, De Keizer MH and De Pauw BE: Procalcitonin does not discriminate infection from inflammation after allogeneic bone marrow transplantation. Clin Diagn Lab Immunol 7: 889-892, 2000.

22. Ortega M, Rovira M, Filella X, et al: Prospective evaluation of procalcitonin in adults with febrile neutropenia after haematopoietic stem cell transplantation. Br J Haematol 126: 372-376, 2004

23. Prieto B, Llorente E, Gonzalez-Pinto I and Alvarez FV: Plasma procalcitonin measured by time-resolved amplified cryptate emission (trace) in liver transplant patients. A prognosis marker of early infectious and non-infectious postoperative complications. Clin Chem Lab Med 46: 660-666, 2008. 